\title{
Research on Product Design Method of Recycling Waste Building Wood
}

\author{
Wenming Liu \\ School of Design and Art, Shenyang Jianzhu University, Shenyang, Liaoning, 110168, China
}

\begin{abstract}
Start from the recycling of waste construction wood, use green design and other sustainable design concepts to study the reuse of construction waste wood in product design. Promote the effective use of construction waste wood resources, so that the residual value of waste construction wood resources can be fully reflected. Discover the material characteristics and advantages of waste construction wood, summarize relevant factors that should be considered in the reuse of waste construction wood in product design, and explore related design methods.
\end{abstract}

\section{Introduction}

As our life enters the information age, the high, fast and accurate pace of life has accelerated the innovation and replacement of the construction industry. While a large amount of wood is consumed, a large amount of waste construction wood is also produced. Compared with China's current timber reserves, there is a serious shortage. Finding a method for recycling from a large amount of waste construction timber has become a new research topic. Therefore, based on the concept of reuse of waste construction wood and the starting point of product design thinking, methods, and strategies, the study of the reuse of waste construction wood in product design provides a direction and choice for reuse of waste construction wood.

\section{Application of waste construction wood in design}

Waste wood usually refers to wood resources that have been discarded and have lost their original use function or value. It includes dead trees in nature, residual waste from industrial processing materials, ship wood dismantled from abandoned ships, wood dismantled from abandoned buildings, waste furniture wood, and disposable chopsticks used in daily life. Among them, the construction industry is a major source of waste construction wood and one of the types of waste wood with reuse value.

Based on the research and analysis of domestic and foreign literature on the recycling of used construction timber, the main way of recycling used construction timber is on the one hand industrial recycling, that is, the production of available plates and other materials through the integration of new technologies and materials. On the other hand, according to different product areas, different forms of waste wood are selected through design methods, and different design methods and design concepts are used for related product design research and development. The literature on the application and utilization of waste construction wood in design is relatively small in China, and it does not form a generalization and arrangement of research on design methods and thinking strategies of waste construction wood in the field of product design.

\section{Material characteristics of waste construction wood compared to new wood}

As a design material, the exploration and research of wood has gone through thousands of years of development. Although it is also a timber resource, after a long period of use, the waste construction wood has the material characteristics that wood does not have. The German philosopher Leibniz once said: "There are no two identical leaves in the world." There are also no identical two pieces of waste construction wood in the world. The comparison of wood resources does not.

\subsection{Appearance comparison}

In terms of texture, first of all, the members of the old building's beams, squares, structures, wooden doors, and windows are exposed all year round. After a long period of weathering, a unique texture will be formed. Compared with new wood, the texture of the texture will be more obvious, the touch will be rougher, and the whole wood will show a deeper visual sense on the grain. Secondly, due to the thermal expansion and contraction caused by the changes in the external environment, the wood will crack and warp, which will enrich the texture

\footnotetext{
"Corresponding author's e-mail: 83373734@qq.com
} 
and texture of the wood surface, making the texture of the waste construction wood material richer.

After a long period of use or disposal of wood, there will be changes. First, wood is a natural material. it is easy to attract insects. Anti-insect treatment, but due to long-term use and disposal, it is very susceptible to secondary worms and leave worm eyes on the surface of the wood.(Fig1) In addition, some non-load-bearing woods usually have knots. Usually in new woods, in order to pursue the strength of the material and the cleanness of the surface texture, the wood with knots is

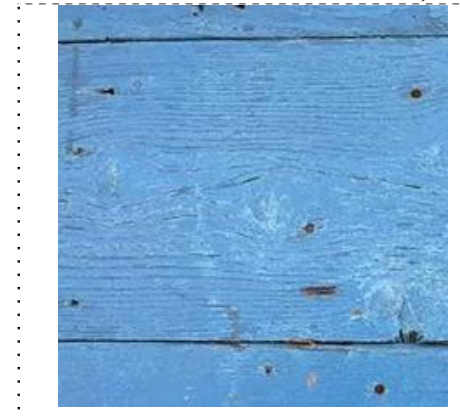

Figure 1. Bug eye

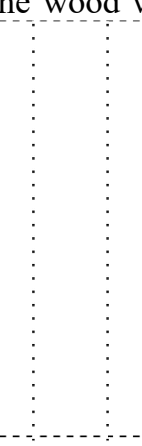

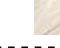

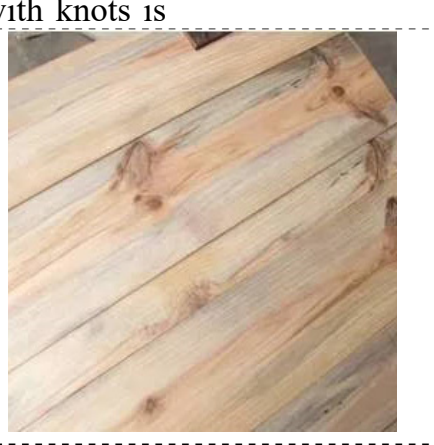

Figure 2. Wood section usually discarded, but its special patterns and structures are Has a high value of artistic processing.(Fig2) In addition to the common defects of the above two types of wood, because of the common shelving of waste construction wood, some plaques may also form on the surface of the material due to oxygen in the air, uneven lighting, pigment deposition.(Fig3) These defects in the processing of new wood materials are exactly their characteristics for the application of waste construction wood.
After a long period of use of some construction and furniture wood, the color of the wood surface will change, the surface color of some wood species will fade, and the wood surface of some tree species will become deeper and darker. There are two main causes of wood discoloration: chemical discoloration and fungal discoloration. Generally, chemical discoloration has no effect on the wood material itself, mainly affecting the surface color of the wood. Most fungal discolorations will affect the mechanical properties of the wood, but will not cause greater damage to the wood.

\subsection{Material comparison}

Wood is usually more susceptible to changes in the external environment. As an anisotropic material, the strength of the grain is relatively high. Therefore, most of the wood is cut in the direction of the grain when the board is processed. In addition to obtaining a straight and rich texture, you can also ensure the strength of the board; in addition, the wood is often mechanically dried or airdried to balance the moisture content of the wood before processing to ensure that the wood will not be caused by too much water. The physical properties are affected.

However, because the indoor and outdoor environment temperature often changes in the building, the long-term temperature change of the wood products will cause the moisture content of the wood to change, and the change in the moisture content directly affects the wood's deformation and swelling and shrinkage, which will affect the wood. The use of a certain amount of problems such as shrinkage can cause wood warpage, cracking, loose joints, loose joints and other problems. According to Xu Minggang's "Experimental Research on the Properties of Old Wood Materials of Ancient Buildings", the material properties of old fir and new fir are compared experimentally. According to the results of experiments, the shrinkage of old fir wood is lower than that of new wood, which means that the same moisture content will cause the wood to deform, and the old wood will have less deformation than the new wood. The compressive strength, compressive strength, flexural strength, and flexural modulus of elasticity of the grain are lower than those of the new fir, and as the moisture content changes, the strength of the new and old wood will increase with the moisture content. As the rate increases, it decreases, but the decline in new wood is even lower. In Chen Guoying's "Research on the Changes of Old Wood Materials and Their Impact on Building Deformation in Ancient Buildings", after rigorous experimental calculations, it was proposed that after hundreds of years of wood influence, the density of wood increased, and the tissue cells of wood became more dense, water is reduced to a very small extent, and therefore, the strength of the wood is also greater than the new wood. On the other hand, the compressive strength of the cross-grain of the wood has been shown in two documents and other relevant information. As the service life of the wood increases, the compressive strength of the cross-grain and the flexural strength of the cross-grain will be weakening, therefore, so the process of product design and application of waste construction wood, the use of waste construction wood as a board material will be affected, and attention should be paid to the use method.

\subsection{Value comparison}

\subsubsection{Economic practicality.}

Except for the wood of the old building and some waste construction wood with high artistic value, in general, compared with the new wood, the source and price of the waste construction wood is cheaper, and the general price is almost double. The specific recycling value 
depends on the wood material types, but in general, it is cheaper to recycle used construction wood than new wood.

\subsubsection{Material value.}

In the field of art processing, artists are more inclined to carve wood with rich materials and textures. The texture unique to waste construction wood makes the material itself more sculptable. The unique material makes the finished product compared to new wood processed products. The visual effect is more artistic. After careful design and modification by designers and artists, the waste construction wood products have higher artistic value, but it is also because of the uniqueness of the waste construction wood that designers and artists can have a better platform to exert their creativity. It can be said that they complement each other. Therefore, the waste construction wood products have extremely high added value in terms of value potential.

\subsubsection{Eco-friendly.}

Waste construction wood belongs to the reuse of waste wood materials. In China, the recycling of waste wood is of great significance to the conservation and utilization of China's wood resources. Recycling waste wood can not only improve the efficiency and use of wood. Rate, consistent with the concept of sustainable development of ecological design and green design, and more importantly, the huge economic burden and environmental pressure brought by waste wood to society can be reduced through the recycling of waste construction wood. So recycling waste wood is very necessary for research and promotion.

\section{Relevant elements for product design using waste construction wood}

Based on the material characteristics of newer construction wood from waste construction wood, in the design of products using waste construction wood as the raw material, based on aesthetic design ideas and concepts, promote the shaping and artistic expression of waste construction wood in products; The way of expression is to rely on and excavate the design connotation of waste construction wood products; to use demand as the purpose, to build the multi-functional fusion of waste construction wood products and to summarize the "communication" between "people and products". By summarizing the design elements of waste construction wood products, it can provide a sufficient theoretical basis for the study of design methods and application examples of product design of waste construction wood products. So aesthetic factors, emotional factors and demand factors are the three design factors that waste construction wood should follow in product design and recycling.

\subsection{Aesthetic elements}

The rule of formal beauty is the summation and abstract summary of the formal laws of beauty in the process of creating beauty and beauty. The law of formal beauty mainly includes the symmetrical balance of form, the simple unification of style and the harmonious contrast of color, and the requirements of proportion, scale, rhythm, rhythm and change. In product design, the study of formal beauty rules helps shape the product in appearance and shape. Mastering the rules of formal beauty can enable people to more consciously use the rules of formal beauty to express the content of beauty, and achieve a high degree of unity between the form of beauty and the content of beauty. Different from the "consciousness" of consciousness, the principle of formal beauty embodies beauty more from a rational perspective.

\subsection{Emotional element}

In product design, product homogeneity is a common problem in the design industry. The fast-paced production line processing has led to product design focusing on simple modeling, functional practicality, and simple processing processes. Similar textures and fixed materials gives people a more "cold" feeling. In this environment of product design, the concept of emotional design is even more precious. The waste construction wood is essentially a kind of "life" material. Whether it is the annual ring that depicts the veins of life in the crosssection of the wood, or the straight and upright ductile veins in the longitudinal cut, it is all about the emotion of wood as a life. Therefore, starting from the concept of emotional design, injecting the emotional soul and vitality into a product is not only a respect for a product, but also a reflection of the intrinsic value of a product.

\subsection{Demand factors}

In product design, the essence of a product is a demand, and the level of demand from low to high also reflects people's change with the overall change of "self-society". It is also reflected in the product design that a product design is functional. Practicality, quality and safety, functional expansion, cultural connotation, and broad recognition are all design concepts and thinking modes that promote the development and perfection of products. Therefore, in the product design of waste construction wood, the demand element is to reflect its core value as a product; it is the mission and responsibility to resolve the contradictions and problems facing people's lives, and it is also the driving force and demand for product design development.

In product design, the essence of a product is a demand, and the level of demand from low to high also reflects people's change with the overall change of "selfsociety". It is also reflected in the product design that a product design is functional. Practicality, quality and safety, functional expansion, cultural connotation, and broad recognition are all design concepts and thinking modes that promote the development and perfection of 
products. Therefore, in the product design of waste construction wood, the demand element is to reflect its core value as a product; it is the mission and responsibility to resolve the contradictions and problems facing people's lives, and it is also the driving force and demand for product design development.

\section{Exploration of Product Design Methods for Recycling Waste Building Wood}

\subsection{Appearance and shape: "show" and "melt"}

\section{"Show"-highlight the material}

Compared with new wood, the biggest feature of waste construction wood is its texture. Whether it is the weathered texture for many years or the insect eyes are special features of waste construction wood. Therefore, in the application of waste construction wood in product design, highlighting the special texture of waste construction wood is the most important design element of waste wood products. Dutch designer Piet Hein Eek once put forward: "The starting point of my design inspiration is often materials. Compared with new materials, the beauty of waste materials is rich in layers. It has traces of time, carrying its own story, each one is unique. "

"Merging"-integrating into the environment

The integration of products in interior spaces has always been an important issue that many product designers overlook. In many cases of interior design, we can often find that the integrity of many interior spaces is very good. Among them, as an important component of interior design the element. For a successful interior design space, the product needs to be highly integrated with the interior space in order to avoid the inconsistency of the single product and the indoor environment. The product design of waste wood due to its own texture problems will appear incompatible with the entire space environment in many interior spaces. To address this problem, on the one hand, designers need to coordinate the construction of the entire space and coordinate the elements, and on the other hand, they need to adopt The products are shaped in an all-round way by shaping the product's shape, polishing the texture, using design methods, and changing design thinking. In the product design of waste construction wood, "fusion" is very important. "Fusion" is not only integrated, but also integrated. Through the processing of waste wood materials, the excavation of material functions, the shaping of product shapes, and the design emotional input, not only can the products be integrated into different spatial environments, but also a reflection of a product design culture.

\subsection{Function and structure: "group" and "spelling"}

"Group"-function combination
In the current furniture design, the "modular" design concept has gradually become a trend. More and more young consumers are paying more attention to choosing modular furniture with comprehensive functions and unique shapes when purchasing furniture products. Through the selection and processing of construction waste wood, combined design can be made to integrate it into the space atmosphere and at the same time have functional, artistic, economic and other characteristics. Combined products are very practical and have strong replaceability.

\section{"Puzzle"-structure stitching}

The structural design of wooden products is very important. Most of the common wooden products in our lives are assembled by splicing. Common splicing methods in life include butt, tenon, inlay, slot and other wood. In addition to the splicing methods, there are many splicing methods for tenon-and-mortise structures. Timber can be glued after splicing to strengthen the structural stability of the wood. Compared with the use of nailing and metal members, the splicing method can avoid damaging the fiber structure of the wood itself, making the wood more durable. In addition, the use of the splicing method is conducive to the replacement and update of product parts, which is of great significance to the extension of the service life of the product and the upgrade of the functionality. Mastering the method of wood split structure can not only increase the beauty of product texture, but also make better use of waste wood to serve product design.

Another method of "spelling" is to use scrap building wood to process and use it as an ornamental decorative artwork. This method can be formed by displaying the unique texture, texture, color, worm eye, and melanin of the used building wood Mottled, scratched and other material features are combined into patterns, and paint can also be used to paint waste wood for artistic creation. The American designer Ariele Alasko uses the waste wood to cut and assemble the wood to create a beautiful pattern and apply it to furniture such as chair backs, bed heads, and dining tables. Feelings and artistic breath rejuvenate the waste wood.

\subsection{Materials and connotations: "matching" and "making"}

"Matching"-material matching

The use of different materials has become an important design method in product design. Visually, the waste construction wood is a relatively simple material. The "precipitation" of time and the "polishing" of the years make the wood's texture more stable and heavy. Under such background conditions, the use or combination of waste construction wood and other modern industrial materials can make the product have more tension on the surface effect; the mutual fusion of different material textures can further reflect the individual characteristics of the product. In the design of waste wood products, there are various types of materials that are commonly mixed and matched. Many designers 
and artists are trying to use different materials and shapes to shape products.

Compared with wood, metal has better abrasion resistance, corrosion resistance, strength, moisture resistance, and is not easy to be damaged. The various surface treatment processes of metal are very suitable for designing and manufacturing products with waste wood, which can be used with waste construction wood. The design of the old, broken, dirty and other characteristics of the fusion, can also cooperate with the waste wood after processing to make a very modern art products. The advantages of using metal and wood are as follows: (1) The structure of metal is generally relatively thin, and it can form a strong visual contrast with the old wood with a strong sense of weight. (2) The stability and strength of the waste construction wood materials are relatively weak, and metal products can be refined, which can not only serve as the basic structure of the waste construction wood products, improve the strength of the product, but also enhance the quality and fineness of the product. Increase the value of waste wood products. (3) The design texture of the product is highlighted through the comparison of materials, and different metal surface treatment processes such as polishing, frosting, and wire drawing can change the visual effect of the product combining metal and waste construction wood, and enhance the product's design and artistic sense. (4) The metal frame structure is stable and high in strength. It can be designed and assembled according to the needs of the product, such as grooves, preparations, screws and other product structures that are easy to replace, which facilitates the replacement and functional upgrade of wood components of waste wood products, thereby extending the product life.

The glass has good permeability, the surface of the material is smooth and smooth, and has a high decorative value. It also has a high-quality texture reflected by material properties such as reflection, flatness, and transparency. Using it with waste building wood can produce a special and wonderful effect that combines simplicity and romance, turbidity and transparency, ancient and modern.

In addition to the two commonly used materials in the field of waste wood product design, there are many other materials such as textiles, plastics, ceramics, cement and other materials that can also be designed with waste wood. Through the interpretation and understanding of related product use functions, the product is innovatively designed with different corresponding materials. The combination of textile and waste wood is very practical in furniture design. The texture of the textile gives a warm and warm feeling. The texture of the wood is also close. The combination of the two materials makes the overall product have a strong affinity and color. Textiles usually use high-grade gray colors, which not only can coordinate well and enrich the color of the overall space, but also the combination of fabric and wood gives the product itself a sense of layering that enhances the value of the product. Plastic is a material commonly used in our lives. It is also widely used in product design. Plastic is lightweight, does not rust, has good impact resistance, has good transparency and abrasion resistance, and has good insulation. Through the integrated design of the advantages of both wood and plastic, the class makes the product more distinctive. The perfect combination of the two materials can also shape the good affinity of the product.

"Make"-create atmosphere

In the product design of waste construction wood, the sensory experience such as the sense of history and staleness conveyed through the reasonable use of the material texture of the waste wood can help product design create an atmosphere. Utilizing the unique texture and texture of waste construction wood to create product designs with sensory experiences such as nostalgia, fun, history, mystery, and art, not only make full use of the material characteristics of waste construction wood, but also make the product become a space in the space. The focus of the vision is unique, enhancing the diversity of design levels and the richness of design elements in the space.

\section{Conclusion}

Based on the above analysis of the recycling of waste construction wood, compared with the design fields of architecture and interior, the volume of objects in product design is smaller, and the requirements for material strength, toughness, specifications, and degree of loss are less limited; The application of waste construction wood is more flexible. Product design covers a wide range of areas, in the field of home life; small to chopsticks, matches, toothpicks to reach home products, automotive interiors, public facilities. So, in terms of the scope of construction wood recycling, there are more options. Not only can the material characteristics of waste construction wood be fully displayed, but also the application efficiency of waste construction wood can be greatly improved. Whether from the view of economy or from the view of practicality, efficiency and design, the reuse of waste building wood in product design is worth studying and popularizing. Establishing and implementing the concept of sustainable development in product design, in particular, has more important significance for advocating low-carbon life and protecting the ecological environment.

\section{References}

1. Su, Y.L, Hu.X.T.(2010) Product form design. Shanghai Science and Technology Press, Shanghai.

2. Zhang, Q.W. (2019) Research on Product Material Image Design Based on Texture Elements. Packaging Engineering, Chongqing.

3. Shigeru Uchida. (2019) Sixty years of Japanese design: 1950-2010. Central Publishing Group, Beijing.

4. Luo, M.(2019) Study on the Slow Life Concept of Modern Wooden Lamp Design. Central South University of Forestry and Technology, Changsha. 
5. Ian\&Geraldine Rudge. (2012) 1,000 interior product designs. Electronic Industry Press, Beijing.

6. Wang.S.X.(2010) Study of Ming Style Furniture. Beijing Sanlian Press, Beijing. 